\title{
Globalización y gobernabilidad en el estado de Dere- cho ¿hay posibilidad de controlar los efectos de la globalización?
}

Alberto Antonio Spota

I. Presupuestos de base para el desarrollo del tema en análisis. Característica fundamental de la globalización en nuestro tiempo.

Primera premisa de análisis: la globalización es realidad instalada y no posibilidad que está llegando.

El fenómeno de la globalización se enuncia en nuestro tiempo, no por todos pero sí por una inmensa mayoría de analistas, como si fuera un tema que está comenzando y que se insinúa en su instalación más o menos inmediata. Esta premisa representa un grave error.

La globalización es una realidad de nuestro tiempo. No es algo que está por llegar o que está llegando. Es algo que existe en plenitud.

Los efectos de la globalización son desparejos de acuerdo a cada sociedad. Esto se debe a que la globalización es una avenida de dos manos.

Como resultado del impacto motivado por su propia existencia, de acuerdo a la potencia del accionar del poder tecnológico en acción o de la dominación económico financiera a la que se refiera, es sustancialmente igual todo a lo largo y ancho del planeta. Pero su resonancia en cada sociedad humana, evidentemente, son diferentes y distintos.

No es lo mismo el efecto de la globalización en una sociedad conformada como estado de derecho razonable, que lo que acaece cuando se impacta en una sociedad de estructura de poder vertical y donde los

"(p) El profesor Alberto Antonio Spota falleció el 27 de sepriembre de 2001. 
derechos humanos no están garantizados, sino en forma muy relativa.

También es diferente el impacto globalizante en una sociedad con un grado cultural avanzado desde el punto de vista tecnológico, científico y de desarrollo educativo razonable, que en una sociedad donde esos valores rigen con niveles inferiores o muy poco trascendentes.

Esta aproximación a la globalización desde el ángulo de visualizarla, no sólo en sus efectos sobre la sociedad humana impactada, sino con referencia a las respuestas que esa comunidad produce al responder al impacto globalizante, requiere para su buena comprensión toda una tipología de no fácil desarrollo.

Es bueno señalar que existe además un manojo de valores y de interrelaciones que se producen dentro del cuado señalado, que a su vez condiciona diversas tonalidades de respuesta.

Entre esos valores o fuerzas relacionantes hay algunos que son de enorme importancia, como por ejemplo la fuerte vigencia o no de creencias religiosas dominantes.

En aquellos supuestos de sociedades compactadas sobre la base de una ideología religiosa trascendente y definitoria, las respuestas al impacto globalizante van delimitar en enorme proporción la capacidad condicionante de la franja de globalización que se analice.

\section{La globalización en sí misma no es un valor ni puede serlo}

Otro error fundamental consiste en pretender calificar a la globalización como buena, mala o regular.

La globalización no debe ser ni puede ser calificada axiológicamente. Es un esfuerzo inútil y sobre todo innecesario para la comprensión del fenómeno.

De la globalización sólo se puede predicar que ella es.

Esto significa que la globalización no es ni buena, ni mala, ni agradable o desagradable.

Los efectos de la globalización podrán tener y tienen ineludiblemente, signos valorativos diferentes y variables.

Entonces, la globalización es.

La globalización resulta realidad no debatible. Carece de valoración en sí misma. Sus efectos, que son múltiples y variados, tendrán el 
signo que le otorgue el ámbito de la realidad humana que recibe ese impacto.

Esto quiere decir que los efectos de la globalización, aunque análogos en muchos casos, tienen resultados disímiles de acuerdo a los destinatarios sobre los que se da esta realidad contemporánea.

De allí que efectos de la globalización tienen consecuencias distintas, aun cuando el impacto sea igual o sustancialmente semejante y originado en la misma franja de poder.

Relacionar globalización con estado de derecho, requiere imprescindiblemente todo un análisis tipológico.

Los efectos de la globalización son totalmente distintos en los estados de derecho contemporáneos, de acuerdo a la consistencia institucional de cada uno de ellos. Y también en relación directa a la capacidad económica, financiera y sobre todo tecnológica de las comunidades humanas organizadas a la manera mentada, donde se produzcan los efectos de la franja globalizada que se analice. Así también habrá que evaluar la consistencia de las ideologías culturales y religiosas que puedan o no señorear en esa sociedad humana.

Queda entonces como fundamental conclusión que los impactos de los efectos de la globalización sobre los estados de derecho contemporáneos son multívocos y fundamentalmente desiguales.

Este análisis está comprobado en la realidad contemporánea, así que se visualizan los efectos de una franja de poder globalizado en distintas comunidades humanas igualmente regidas como estado de derecho en nuestro tiempo.

III: Elemento o característica determinante que condiciona los efectos de la globalización. Su intensidad y trascendencia en los estados de derecho contemporáneos.

Evidentemente la globalización encuentra una valla muy importante en sus efectos cuando los estados de derecho sobre los que la franja de poder globalizado actúa se encuentran fuertemente intervinculados.

Esto es, las comunidades políticas o económicas como la Unión Europea, tienen una capacidad de reacción y una manera de responder a los impactos de las franjas de globalización, totalmente diferentes a 
estructuras político jurídicas, que aunque asuman con más o menos realidad la forma de estado de derecho, no integren asociaciones comunitarias. Puede o no mediar analogía con los efectos de la globalización sobre estados de derecho que tienen alta tecnología y capacidad financiera, pero que al no integrar unidades políticas o económicas, ese aislacionismo dará posible y notable respuesta diferente.

Es evidente que para esos supuestos aislacionistas la eficacia de la contestación a la globalización no gozará de la misma consistencia y efectividad.

\section{Primer intento de síntesis de respuesta al estudio de las relaciones entre globalización y estado de derecho y gobernabilidad.}

Todas estas variables muestran la enorme dificultad para responder a la pregunta central inicial. Máxime en el sentido de analizar las relaciones y los efectos de la globalización y la gobernabilidad en los estados de derecho contemporáneos.

Esto es, la globalización es una realidad contemporánea que tiene distinta intensidad en sus efectos en las diferentes comunidades que forman la humanidad de nuestro tiempo.

Pero la globalización, como lo he dicho y repetido, no puede ser pensada como algo que está llegando, sino como una realidad existencial en plena vigencia. Como fue expuesto con variables en la intensidad de sus consecuencias.

Es de trascendencia subrayar los señalamientos que preceden. Pues de otra manera, como acaece en muchos comentarios referidos a esta temática, se da la equivocada impresión que el fenómeno universal y condicionante de la globalización, estaría recién golpeando la puerta de las sociedades y no como en verdad sucede que esta realidad ya ha ingresado en plenitud en nuestro tiempo en todas las organizaciones humanas, cualquiera sea su forma de gobierno o su estado de desarro1lo. Lo expuesto vale como primera conclusión todo a lo ancho del planeta Tierra y con efectos variables en su intensidad, pero innegables en su existencia y definitorios en sus consecuencias.

Y con relación a la gobernabilidad las distintas respuestas que el análisis de los efectos de la globalización produzca dará al propio tiempo 
consecuencias bien diferentes con referencia a la gobernabilidad posible en aquellos estados de derecho donde la globalización impacte. Pero cualquiera sea la naturaleza de la estructura de forma de gobierno o de forma de estado, la gobernabilidad se verá fuertemente condicionada sin excepción en cada comunidad humana.

La globalización encuadra y delimita la capacidad decisoria de todos los gobiernos contemporáneos. Lo expuesto integra la primer conclusión de este trabajo.

V. Segunda premisa de análisis: la globalización es un fenómeno contemporáneo entre cuyas características más trascendentes se encuentra la que señala y muestra que los efectos de la globalización no tienen hasta este momento oponente efectivo y con calidad de adversario equilibrante

La historia muestra que en todos los procesos de condicionamiento de las sociedades humanas, cualquiera sea la forma de impacto o dominación que los mismos adoptaron, recibe como contrapartida en algún momento una resistencia de características diferentes en cada caso, pero que analizada en perspectiva, adquiere dimensiones históricas más o menos proporcionales al impacto recibido.

No importa que esos adversarios o enemigos tengan proporciones de capacidad de enfrentamiento equiparables o no a las nuevas fuerzas a enfrentar. Lo trascendente es que no hay en la historia del mundo ejemplo de movimientos dominantes como es la globalización, que no tenga antagonistas más o menos importantes y contra los que esa fuerza libra batalla con éxito variable.

La globalización tiene la característica extraordinaria que no ha generado hasta hoy en sus orígenes fuerzas de oposición de verdadera importancia y trascendencia.

Recién en estos últimos tiempos aparecen formas larvadas de enfrentamiento a la globalización, muchas de ellas más discursivas que efectivas.

El único señalamiento que merece ser destacado en el ámbito de la temática en desarrollo, radica en comenzar a visualizar que las reacciones más importantes a la globalización se dan en determinados aspectos culturales. 
Esto es de manera más o menos parecida al análisis que hace alrededor de cincuenta años efectuara Arnold Joseph Toynbee (1889-1975) en sus "Estudios de Historia» cuando analizaba las colisiones entre diversas culturas. Allí señaló que el vencedor era siempre de mayor fortaleza en los aspectos tecnológicos. Por ello triunfaba en los campos de batalla. Mientras que las culturas vencidas mostraban su mayor reciedumbre opositora en el núcleo de sus creencias básicas. Esto es en aspectos culturales profundos vinculados a mitos, religiones y creencias. La gran resistencia a la fuerza vencedora triunfante en todas las variables de la tecnología, se encontraba frenada en esas franjas de creencias de las sociedades dominadas.

De la misma suerte, la globalización encuentra opositores de manera muy esporádica y con clara falta de homogeneidad y organización defensiva en determinados aspectos vinculados sobre todo a lo que genéricamente se denominan ideologías nacionalistas. $\mathrm{O}$ si se quiere apego marcado a específicas costumbres ancestrales en función de un sistema de lealtades verticales a la tierra que se habita. Y a lo que se valora como sus mitos profundos y más valiosos. Formas y ritos religiosos revisten aspectos de importante virulencia para enfrentar los efectos desbastadores dominantes de la globalización.

Pero como se ha dicho al comienzo de este capítulo, no existen al menos hasta ahora formas más o menos organizadas de resistencia y oposición a la globalización. Los regionalismos míticos o místicos, religiosos o de costumbres, tienen todavía mucho más de anecdótico que de eficiente. Sin olvidar que ya comienzan a evidenciarse con virulencia determinadas tendencias al uso indiscriminado de la fuerza más o menos anárquica. Pero la eficacia para la oposición a la globalización, no se muestra de manera alguna hasta hoy. Esto es las fuerzas de oposición, aunque puedan en ciertas circunstancias y lugares del planeta significar enfrentamientos sangrientos, están muy lejos de exhibir eficacia que intente sino igualar, al menos controlar, algunos aspectos de la globalización triunfante.

Dicho de otra suerte, la globalización en sus franjas de dominio no tiene oponente valioso en nuestro tiempo, al menos que se lo pueda visualizar.

Buen ejemplo de lo que va expuesto lo evidencian los métodos y formas de la tecnología volcada a las comunicaciones y al dominio de los espacios publicitarios o de conocimiento. 
La globalización que importa las formas y maneras de internet, correo electrónico y en general de uso de lo que se denomina las páginas web, no encuentra opositor eficiente o eficaz de ningún valimiento comparable.

Tampoco las franjas de dominación, resultado de las investigaciones de ciencias puras aplicadas a la química o a la física, a través tanto de la farmacopea humana, cuanto de la creación de bienes que representan el resultado de altísima tecnología, apetecidos en todo el planeta, no encuentran de manera alguna, opositor que enfrente el dominio innegable de la franja de poder que en el ámbito que proceda la globalización produce en todos los rincones del planeta. Es el caso también de las tecnologías referidas a las comunicaciones satelitales. Y en especial las relacionadas con las tecnologías electrónicas a las que he mentado que ingresaron en todos los ámbitos geográficos y culturales sin posibilidad alguna hasta ahora de contradictorio eficaz.

Esto significa entender que la globalización en las franjas de poder tecnológico dominante supera no solamente a todas las formas de concentración de poder político, sino también a todas las estructuras de los estados naciones más desarrollados de nuestro tiempo.

Es necesario comprender que la globalización en las franjas de poder tecnológico, económico, financiero o de comunicaciones es extraordinariamente más poderosa que el más potente de los estados contemporáneos.

Y además cada franja de dominación en el ámbito globalizado, en los hechos, carece de la capacidad de ser controlada, al menos hasta ahora.

De allí que para responder a la influencia de la globalización sobre la gobernabilidad, corresponde señalar y subrayar que en las franjas de poder de alta tecnología como las comunicaciones, internet, correo electrónico y los aspectos relacionados con las investigaciones puras aplicadas en sus consecuencias a la medicina humana, el condicionamiento de la gobernabilidad a esas franjas de poder es casi total. 


\section{Características del proceso globalizante que lleva inexorablemen- te a la concentración de poder y sus consecuencias. Posibilidad que se vislumbra para compensar o al menos para disminuir los efec- tos de la globalización sobre la gobernabilidad.}

Encontramos como ejemplo casi diario las permanentes fusiones de empresas análogas o semejantes en el ámbito de sus actividades.

Nunca en el mundo se ha mostrado tal cantidad de aglutinaciones societarias de enormes dimensiones como en nuestro tiempo.

Esto se debe a que en cada franja de poder de globalización, las grandes concentraciones tecnológicas, económicas o financieras, tienden más que a enfrentarse a unificarse aliándose para de esta suerte mantener la dominación global de la franja que a cada tipo de actividad le corresponda.

Un análisis sereno y en profundidad, tomando a la historia como norma conductora, lleva a visualizar que la única real posibilidad de enfrenamiento a las franjas de poder globalizado, está referida a las consecuencias de las disidencias internas en cada una de las franjas de poder dominante.

No hay ninguna razón para suponer que la globalización, como hecho humano que es, no lleve dentro de sí su propia y contradictoria fuerza opositora. En definitiva, los agentes de la globalización son seres humanos iguales a los otros.

Esto es la globalización de acuerdo a la franja de poder que corresponda en determinado momento, encontrará oposición y control y su poder será condicionado o vencido o al menos mutado en sus esencias, en relación directa a las disidencias internas que se produzcan dentro de los centros dominantes de cada franja globalizada.

Así no hay ningún ejemplo en la historia que contradiga que cuando un poder político en cualquiera de sus formas se convierte en dominante absoluto y carece de contradictor, es justamente desde las entrañas de ese poder donde nacerá el principio que accionará la destrucción de esa dominación.

La globalización por franjas, consecuencia de la investigación científica en el ámbito de las ciencias puras, cuyos efectos se vuelcan luego a las ciencias de aplicación, se convierte en poder político en relación directa a la aplicación de esos descubrimientos y progresos científicos transformados en bienes de uso para el hombre. 
En síntesis, las franjas de globalización son siempre ámbito de poder político. Estas si se quiere hacen del poder político su instrumento de dominación. De allí que sea difícil y sobre todo inútil tratar de diferenciar en el plano que va en análisis si globalización y poder político son o no son lo mismo. Sus efectos sin duda serán los mismos.

Y evidentemente siendo la globalización el resultado de la inteligencia aplicada en sus grados más notables, es perfectamente comprensible deducir que esa misma inteligencia que organiza la franja de poder dominante como consecuencia de las características de la naturaleza humana formará sus antítesis en su propio seno.

En definitiva y al final los procesos de globalización por más tecnología y automaticidad y consiguiente autosuficiencia en su dinámica de desarrollo y aplicación son obra de seres humanos. Quiere esto decir que vista la globalización desde sus centros de poder, esto es su quinta esencia decisoria, siempre y en forma ineludible, las manijas de comando de toda franja globalizada estarán en manos de hombres de carne y huesos.

Y como fue dicho, la historia enseña que los hombres por más geniales que se les reconozca individualmente, sufren los avatares propios de su condición humana. Y si no ellos sus sucesores, que son ineludibles en su existencia y en las consecuencias de su accionar.

Cuanto más agudo, notable y profundo sea el poder de la franja globalizada dominante, más seguro será que la contradictoria de esa franja de poder vendrá de su propio seno. El tiempo en que acaecerá el proceso de enfrentamiento o mutación variará de acuerdo a las características singulares de cada centro de poder globalizado en análisis. La única norma de aplicación difícilmente eludible, es que los contradictores se harán presentes dentro del centro decisorio como consecuencia de la mayor rigidez e intensidad con que se comande en la franja que se considere.

Y si a la reflexión que precede se agrega que es característica de la globalización que la tecnología asentada en ciencias puras aplicadas, constituye la esencia de esa franja de poder dominante resulta que, sin excepción, la tecnología que condiciona esa franja de poder dominante necesita permanentemente mejorarse y retroalimentarse.

En ese proceso de mejoramiento y retroalimentación se dará uno de los campos donde la franja de globalización en análisis encontrará una de las formas de sus antagonismos o de sus contradicciones. Quie- 
re lo expuesto decir que por esa senda llegará su proceso de enfrentamiento y destrucción. O al menos sus mutaciones más o menos profundas que modificarán todas las relaciones de poder dentro de las franjas y con consecuencias en las zonas en que ese poder condicionará la gobernabilidad de comunidades humanas.

No hay ningún ejemplo en la historia de la humanidad que demuestre la posibilidad de subsistencia eterna de un poder absoluto.

Todo poder absoluto tiene poca durabilidad.

La falta de controles internos y externos, que son característicos del poder absoluto, llevan a su autodestrucción.

No existe en toda la historia conocida ejemplo que contradiga el principio que todo poder absoluto se corrompe y se destruye.

Consecuentemente la globalización que por esencia hasta hoy no acepta control ni contradictorio racional proporcional o eficaz y que tiende a desarrollar sus actividades en función de la concentración del poder y sus avatares, tiene en esa caracterización señalada su más grande debilidad. Y la seguridad de su propia autodestrucción, o al menos de su mutación notable.

\section{La globalización como forma de dominación}

Las características enunciadas llevan a que la globalización en nuestro tiempo muestra que sin lugar a dudas es la forma de dominación política más poderosa que el hombre ha conocido y conoce desde que existe historia escrita. Ni los más fuertes y definidos imperios que la historia nos muestra han tenido jamás el poder indiscriminado de dominación indiscutible que tienen hoy cada una de las franjas de globalización.

Una conceptualización fácil lleva a afirmar que la globalización contemporánea es el nombre actual del viejo imperialismo.

Esa afirmación tiene algo de verdad y mucho de desacierto. Además confunde o tiende a confundir sobre la esencia de lo que es la globalización.

El imperialismo que el mundo ha conocido desde que se lleva cuenta de los hechos históricos tuvo por característica, sin excepciones, que el poder imperial de turno dominó en plenitud a las naciones o comunidades que cayeron bajo su égida sobre la base de la fuerza física en 
acción. El antiguo imperialismo tomó y condicionó todo el quehacer de los pueblos dominados. Desde lo tecnológico hasta lo demográfico, pasando por todos los aspectos de producción, concentración y distribución de riqueza, cualquier que ella sea.

Los imperios que la historia ha conocido han tenido mayor o menor habilidad de gobierno para con los pueblos dominados.

El mejor ejemplo que la historia conoce de gobernabilidad eficaz de imperio dominante es el caso del Imperio romano. Roma dominó el mundo por muchos siglos, casi siete, con la característica esencial y fundamental que importó comprender que su dominación política debía dejar espacio suficiente a los pueblos dominados para que ellos tuvieran la sensación de autogobernarse en medida razonable. Fue así que Roma supo, usando de la técnica política que va señalada, ir absorbiendo sin enfrentamientos sangrientos permanentes, a los pueblos dominados, que fueron aceptando la superior cultura en todos los aspectos posibles de ese poder mundial imperial. Junto con otorgar a los pueblos dominados la sensación que mantenían su autogobiernos Roma supo respetar los mitos y las religiones de los pueblos dominados. Lejos de imponer sus creencias religiosas, más bien fue adoptando y adaptando para sí los mitos, las creencias y muchas de las religiones de los pueblos dominados. Entre la sensación de autogobierno, más la aceptación de pluralismos de creencias y la evidente superioridad técnica y jurídica de las estructuras romanas, más los beneficios de la paz general que trajo el comercio entre los pueblos, el imperio se consolidó y duró muchas centurias.

Su crisis se produjo, no como consecuencia de sus formas de dominación, sino casualmente porque al adoptar y adaptarse a los pueblos dominados fue perdiendo su propia esencia de capacidad de gobierno mundial y de dominio. Roma fue en los hechos tomada desde adentro de su propia cultura por los pueblos vencidos, que en la realidad pasaron de una a otra manera a convertirse en dominantes de su dominador.

Fuera del ejemplo extraordinario de Roma todos los otros imperios que el mundo ha conocido en Occidente y en Oriente tuvieron una muy inferior calidad política para gobernar a los pueblos dominados. Además duraron muchísimo menos tiempo y pecaron por ineficacia. Pero la característica general de todos los imperios que el mundo ha conocido hasta hoy, tiende a demostrar y subrayar que el imperio dominante, reitero, con excepción del romano, intentó siempre condicionar en todas sus formas a los vencidos. 
$Y$ es del caso recordar que en todos esos imperios su destrucción vino por lo general de las concentraciones de poder producidas en su seno que le llevaron a los más grandes errores y a caer vencidos por un nuevo poder externo más eficaz y compactado.

La globalización sin duda semeja al viejo imperialismo en tanto y cuanto en la franja tecnológica, económica o financiera o la que le corresponda no acepta competencia y se siente autosuficiente.

Más acaece que la globalización solo está efectivamente interesada en su aplicación y crecimiento de dominación en la franja de poder que corresponde a su propia especialidad. No le importan ni le interesan, sino muy tangencialmente, otras zonas de dominación, sean ellas tecnológicas, económicas, financieras o inclusive demográficas. La globalización domina y solo le interesa dominar lo propio. Al menos hasta ahora prefiere convivir en las diversas sociedades humanas dominantes con otras franjas de poder globalizado, distribuyendo sus respectivas competencias de acuerdo a sus medios de especialización. Esta es la gran diferencia entre la globalización en nuestro tiempo y los imperialismos de otros siglos.

Bueno es precisar que siendo la globalización contemporánea el resultado sobre todo de la investigación pura aplicada a ámbitos del quehacer y necesidades humanas, su franja de dominación tiende a fortificarse sobre la base de su especialización. Cuanto mayor desarrollo científico y tecnológico se logre en cada franja globalizada con relación a su propia especialización, más poder se habrá acumulado.

De allí que la expansión de las franjas de poder de cada globalización se refiera en cada caso a su propia especialización y cuanto más profundicen su ámbito de ciencia pura aplicado, más poder concentrarán. Dicho de otra suerte la franja de poder globalizado tiende a crecer para adentro y no a expandirse a competir con otras franjas de poder.

Para el supuesto que la expansión interna de cada franja de poder globalizado lleve por razón de los progresos investigativos de su propio ámbito a ingresar en el sujeto de otra franja de poder, seguramente se repetirá el curso de acción que ya se ha dado y se da. Así como se han producido y producen enormes concentraciones dentro de cada franja de poder globalizado, que admiran a la humanidad por la potencia de quienes se asocian, seguramente acaecerá algo análogo cuando hay franjas de poder globalizado. 
Las franjas de poder globalizado consecuencia de la evolución y nuevos descubrimientos aplicados de las ciencias puras a sus respectivas especialidades se unirán produciendo una nueva franja de mega poder. El origen científico de la globalización lleva necesariamente a que los progresos tecnológicos desemboquen en esas fusiones, por su propio origen y su dinámica de desarrollo. El poder basado en la ciencia acaba siendo condicionado por las ciencias y sus consecuencias.

No es conveniente en el análisis que se está realizando intentar procesos propios de lo que se llama "ucronia». Esto es, imaginar las variables que habrían acaecido en la historia si los hechos conocidos y que hacen esa historia se hubieran dado de otra suerte. Por ejemplo qué es lo que habría sucedido en la historia del mundo si Napoleón en cambio de haber sido vencido en Waterloo hubiera resultado vencedor. El intento de análisis de las variables posibles en el supuesto enunciado, no tiene interés científico. De allí que entiendo que en este momento los procesos de globalización, frente al supuesto sugerido, más que intentos de respuesta merecen ser situaciones expuestas o explicitadas con respuestas abiertas.

Para acabar este capítulo que pretende de alguna manera comparar a las franjas de globalización con los antiguos imperialismos de dominación, procede señalar que la globalización contemporánea no se ha dado, como lo he dicho, como el viejo imperialismo como el resultado exitoso del uso de la fuerza física de un pueblo sobre otro. La globalización es la consecuencia natural de los avances de las ciencias puras. Y de la aplicación de alguna de sus conclusiones o consecuencias al ámbito de superación de necesidades humanas.

La diferencia entre el viejo imperialismo asentado exclusivamente en la fuerza y las franjas de globalización, que tienen su origen en la ciencia, conforman todo el devenir de los efectos de esta última. De allí que la gobernabilidad de nuestro tiempo condicionada por las franjas de poder globalizado tiene característica totalmente diferente a la que dependía del viejo imperialismo.

En los dos casos hay fuerza de por medio. En los dos supuestos el fuerte condiciona al débil. Pero el viejo imperialismo necesitaba exhibir y aplicar su fuerza física permanentemente. La globalización por franjas domina por la calidad superior de la ciencia aplicada.

Esto es la globalización es sin duda la consecuencia de la inteligencia pura y aplicada. Como tal resulta más poderosa y condiciona la gobernabilidad con mayor intensidad que el viejo imperialismo. 
Es claro que esos desarrollos científicos y tecnológicos se produjeron cada uno de ellos necesariamente en el ámbito territorial de los estados contemporáneos políticamente dominantes. Y desde el punto de vista geográfico sobre todo en esta segunda mitad del siglo XX que acaba casi con exclusividad en el contexto del único gran poder político que domina el mundo. Me refiero a los Estados Unidos de la América del Norte. Ha llegado a ser el poder imperial a la vieja manera de mayor capacidad en el mundo y sin contrincante a la vista, sobre todo luego del 9 de noviembre de 1989 en que cayó el muro de Berlín y poco tiempo después se desintegró la Unión de Repúblicas Socialistas Soviéticas.

Pero sucede que las franjas de poder globalizado, que tienen su asiento en los desarrollos de las ciencias puras y de las aplicadas, crecieron y dieron sus resultados exitosos en el ámbito territorial de los Estados Unidos de América del Norte, ofrecen a esa nación un poder dominante hoy superior a su propia capacidad bélica.

La gran característica de las franjas de poder de la globalización es que ellas abarcan como centro dominante también a los propios Estados Unidos de América del Norte.

Esto es las franjas de poder globalizado, aunque parezca increíble en nuestro tiempo, pueden enfrentar y a veces enfrentan al propio poder político estadounidense.

Sucede así porque la globalización tiende cada vez más a desvincular su franja de dominación de toda bandera o territorio político.

Las franjas de globalización pueden llegar a enfrentarse o a coincidir, más allá y más acá de las soberanías nacionales.

La globalización en el mundo contemporáneo crea una nueva manera de dominación política a través de lo tecnológico que excede y supera a las fronteras políticas. La globalización por franjas crea un sistema de lealtades con consecuencias políticas totalmente diferentes a las antiguas dominaciones imperiales.

Ese sistema de lealtades está referido a la propia franja de globalización en su centro decisorio, por sobre las relaciones de bandera o territorialidad. Aunque no guste, las franjas de poder globalizado y sus efectos circulan por ámbitos totalmente distintos a los estados naciones en la inmensa mayoría de los supuestos. Podrá haber alguna excepción circunstancial. Pero con poca durabilidad. 
La globalización entonces tiene una característica fundamental. Es en los hechos la quinta esencia de la aplicación material de la inteligencia científica. De allí su fuerza y su casi indestructibilidad.

Las franjas de dominación que evidencia la globalización contemporánea en las distintas zonas de actividad en las que actúa, desarrollan su extraordinaria potencia que obliga para enfrentarla, metodologías de muy difícil aplicación durante larguísimo tiempo y con altos costos y personal humano eficiente y adecuado. $Y$ sobe todo estudios de ciencias puras y luego de ciencias aplicadas para poder superar, exitosamente, a los dominantes actuales de la franja de globalización que se estudie o analice.

Como resulta prácticamente imposible en estos tiempos producir con eficacia estudios de ciencias puras y de ciencias aplicadas, como los que se han desarrollado y se continúan desarrollando en los centros de poder tecnológicos en los que han tenido su origen las actuales franjas de poder globalizado, la conclusión es que guste o no guste hoy por hoy y en nuestro tiempo, franjas de poder globalizado, no sólo son casi indestructibles, sino que cada vez serán más poderosas. Su finiquitación está relacionada a mis ojos con exclusividad a los supuestos analizados en el capítulo precedente.

Por estas razones es un error señalar que la globalización es la forma actual del imperialismo. Esa afirmación lleva dentro de sí el convencimiento que como todo imperialismo acaba vencido por otro, pues la historia así lo enseña hasta ahora, o se destruye desde adentro, como acaeció con el imperio romano o muy recientemente con la Unión de Repúblicas Socialistas Soviéticas, la globalización también caería de manera igual o análoga a las distintas formas imperiales señaladas.

No es así. La globalización por franjas que exhibe la contemporaneidad, hasta este momento no parece destructible, sino en la medida en que sea acertado el análisis expuesto en el capítulo precedente con referencia a esa temática. Al revés parece dar la sensación que cada vez es más fuerte, más dominante. No da signos de debilidad, sino todo lo contrario. Muestra que cada vez los centros de poder tecnológicos que crearon y que dominan las franjas de globalización tienen mayor capacidad de crecimiento científico y en su consecuencia mayor poder de dominación.

Dicho de otra suerte no aparecen por este camino enemigos o contradictores, como tuvieron todas las viejas formas imperiales. 
Estoy muy lejos de afirmar que la globalización por franjas es indestructible y definitiva. No es así. Jamás mantendría ese punto de vista. Por cuanto el análisis de la historia enseña que todas las sociedades humanas tienen extraordinarias mutaciones que producen transformaciones increíbles y totalmente impensadas.

Con esto quiero significar que hoy por hoy no se está en condiciones de señalar cuáles son los contradictores de la globalización y que no sea lo analizado en el capítulo precedente al efecto. Y menos cuáles serían las posibilidades de mutación que esa globalización por franjas podría sufrir en un futuro inmediato o más o menos mediato.

Hoy por hoy no hay otra respuesta posible con asiento científico razonable que la señalada.

Todo esto lleva necesariamente a comenzar a responder a la temática de globalización y estado de derecho y gobernabilidad de manera que de alguna forma debe producirse respuesta con alguna coherencia equilibrada a través de las premisas expuestas más arriba.

\section{VIII. ¿Qué denomino globalización por franjas? El origen posible de la globalización.}

Antes de pasar a otras respuestas posibles a la temática de globalización y estado de derecho y gobernabilidad y visto que en numerosas oportunidades precedentemente he señalado que la globalización se produce por franjas en el mundo contemporáneo, procede que intente explicitar qué quiero decir cuando señalo que la globalización no es un proceso unívoco general, totalizador y con un centro único de poder.

Cuando menciono globalización por franjas quiero significar que como consecuencia del enorme crecimiento del conocimiento científico, sobre todo en la segunda mitad del siglo XX, se han desarrollado centros de estudios de ciencias puras que tienen sin duda interrelaciones, pero que al mismo tiempo poseen fuertes individualizaciones que los distingue y les da características propias.

El hombre de occidente en el siglo XX produjo al menos tres grandes invasiones gracias a sus adelantos en las ciencias puras. Acá está el cuadro de origen fundamental quizá no único, pero sí decisorio, de los 
orígenes de la globalización. Esas tres grandes invasiones dominaron ámbitos que el ser humano jamás había llegado a otear y menos poder manipular y decidir.

En el siglo XX el hombre ha invadido el cosmos. En eso está en estos tiempos.

La invasión al cosmos ha asumido proporciones inimaginables en todo el pasado. El hombre conoce aspectos de inmensidad del cosmos que eran totalmente ignorados. Y lo que es más ni siquiera pensados como posibles. En esa invasión al cosmos se está en estos tiempos golpeando puertas extrañísimas que van desde intentar demostrar que el universo está en permanente expansión, hasta afirmar la posibilidad de mostrar y visualizar las distintas etapas que el cosmos ha tenido desde lo que pudo haber sido su origen. La invasión al cosmos tiene dimensiones impresionantes y además puede dar respuestas también impensables a la posibilidad de distribución del hombre en zonas del cosmos más allá de la tierra. Ese ámbito de invasión y descubrimiento, ubicado originariamente en el cuadro de las matemáticas y también de otras ciencias puras, ofrece permanentemente aplicaciones para la vida cotidiana. Por razones de vinculación científica inmediata y mediata la invasión al cosmos desarrolló tecnologías de punta y de extraordinaria eficacia y aplicación inmediata que pueden llegar a crear y ya están creando fuentes de energía y formas y maneras de comunicación a más de reestructuraciones de la materia. En este último campo la segunda gran invasión a la que luego me referiré y que denomino la invasión al átomo, crea franjas de poder globalizado con tecnología tan extraordinaria que realmente la imaginación queda detrás de las posibilidades que los científicos ya están dando. La invasión del hombre al átomo es un ámbito de creación permanente de franjas de poder tecnológico de aplicación a la vida contemporánea que altera a diario enormes aspectos positivos y también negativos de conocimientos, eficacia y fuerza.

La energía, la alteración de la materia en sí misma y las transmutaciones que la invasión al átomo están posibilitando al hombre, importa la segunda gran invasión que otorga en sus aspectos de aplicación globalizada otras franjas de poder. Exceden esas franjas de poder hasta lo inimaginable las capacidades y los resultados concebidos originalmente.

La tercera y enorme invasión que el hombre ha producido lo es a la genética. 
Quizá este proceso de ciencia pura y de conocimiento y de ciencia aplicada sea en los hechos la más trágica de todas las franjas de poder globalizado. El hombre ha ingresado para bien o para mal en los misterios de la vida en sus orígenes y en sus mutaciones posibles. Los ámbitos de aplicación llegan desde lo maravilloso hasta el horror. Las ciencias vinculadas con el arte de curar y sus variables posibles ofrecen en las franjas de globalización que corresponden a esta invasión a la genética, capacidades que lindan con lo que está más allá de lo humanamente aceptable.

Estas tres grandes invasiones que en forma muy sintética he enunciado, muestran que las franjas de globalización tienen evidente autonomía e independencia entre ellas, que no sólo superan todas las fronteras territoriales y políticas, sino también, y esto es lo más peligroso, las propias fronteras no ya de las creencias religiosas, sino de los presupuestos básicos de la cultura que el hombre ha podido ir construyendo desde que hay historia hasta hoy.

Quiere esto decir que las franjas de globalización en nuestro tiempo a más de su enorme poderío, de su independencia y de su superioridad a todo tipo de fronteras políticas y sociales, ingresan también a la capacidad de superar limitaciones éticas que pueden hacer no solamente a creencias de base, sino también a las estructuras fundamentales del estado de derecho, que se asienta en el principio filosófico que todo hombre y toda mujer es un fin en sí mismo por su sola condición de tal.

Toda la estructura de los llamados derechos humanos parte de esta afirmación filosófico dogmática. Tiende a visualizar que cada ser humano no sólo es un fin en sí mismo, sino que importa la permanente capacidad de su propio mejoramiento sobre la base de los presupuestos de ética y solidaridad que llevan a la persona humana a niveles de equilibrio que posibiliten la convivencia pacífica y progresivamente jerarquizable en el ámbito de los valores más valiosos y profundos.

Todo el contexto de lo que va descripto está colocado evidentemente, frente a posibilidades positivas y también lamentablemente profundamente negativas.

Esto es, como ya se mantuvo en este trabajo, la globalización no tiene en sí misma signo de valoración positivo o negativo.

Son sus efectos de acuerdo a las circunstancias y contingencias los que pueden dar respuesta a los valores. 
Y todo este extraordinario escenario originado por la globalización, se produce en franjas de especialidades.

Esto es teniendo su origen en lo que he llamado las tres grandes invasiones del hombre de nuestro tiempo, la globalización como resultado de esos procesos de ciencias puras y luego de ciencias aplicadas se $\mathrm{da}$ en el mundo de nuestro tiempo, como bandas individualizadas y superpuestas. Pero con individualidad en lo que se refiere a la titularidad del poder que desde cada una de esas franjas se ejerce sobre la humanidad, superando como se ha dicho y repetido fronteras geográficas, políticas y también éticas, morales y tecnológicas.

La globalización por franjas entonces es en nuestro tiempo una característica típica de la globalización.

La globalización es la manera de denominar en forma más o menos genérica la visualización de las franjas de poder tecnológico, económico, financiero o de la naturaleza que fuere con las implicancias sociales, políticas, éticas y de costumbres que han sido señaladas.

Globalización por franjas significa entonces reconocer que no hay una globalización. Si no un conjunto de franjas de poder en cada uno de los ámbitos señalados. Quedándose al unísono en un mismo tiempo histórico se condiciona a toda la población humana colectiva e individualmente.

Ese condicionamiento es en nuestro tiempo inexorable. Nos guste o no nos guste reconocerlo.

Lo expuesto quiere además decir que la globalización por franjas no tiene, por lo menos hasta nuestro tiempo, posibilidad de enfrentamiento que no sea las concentraciones comunitarias que en su propia existencia y de acuerdo a su compactación, como sucede con la Comunidad Europea, pueden relativamente disminuir los impactos de esas franjas de poder globalizado.

\section{La globalización y la gobernabilidad en el estado de derecho.}

Los capítulos que van expuestos muestran que las globalizaciones por franjas, al menos a mi criterio y dicho con respecto a opiniones que no coincidan con esta visión, no sólo superan las antiguas soberanías políticas y territoriales, sino todas las formas de convivencia. 
Como nunca, la humanidad está presenciando la vigencia de franjas de poder que ingresan en la vida diaria de cada hombre y de cada mujer y más que influir sobre cada vida llegan a conformar de manera directa o indirecta los propios valores y las características de las personalidades de todo ser humano.

Los sistemas globalizados de comunicación en todas sus formas, desde Internet hasta las distintas variables de los poderes electrónicos aplicados a las comunicaciones, ingresan, golpean, conforman y si se quiere deforman todas las personalidades humanas en todas las latitudes del planeta Tierra.

Se universalizan no sólo noticias, sino formas y maneras de vida y lo que es peor o más preocupante se tiende a homogeneizar o distorsionar toda la estructura de valores de los pueblos contemporáneos.

Sin duda corresponde señalar que existen centros culturales de resistencia y sobre la base fundamentalmente de procesos ideológicos y religiosos propios de sociedades por lo general de bajo nivel tecnológico.

Sociedades que aparecen ofreciendo mayor resistencia o al menos aparente a las franjas de globalización, como en el ejemplo ya recordado de Toynbee, intentan refugiar sus singularidades en los valores más profundos de sus culturas autóctonas.

Pero los campos tecnológicos de dominación en las zonas blandas de las ciencias aplicadas, donde esas sociedades primitivas son enormemente débiles, producen en forma lenta pero continuada episodios de mutación que tienden a modificar los valores más arraigados y profundos.

En esta materia la fuerza expansiva de los medios electrónicos de comunicación, más todos los aspectos de las ciencias vinculadas al cuidado de la vida humana, van condicionando y transformando aquellos valores de base.

En las sociedades conformadas como estado de derecho, las estructuras jurídico políticas propias de ese sistema de mando y obediencia, no están preparadas para contrarrestar los efectos deletéreos de las franjas de poder de la globalización.

Los estados de derecho no tienen estructuras políticas ni jurídicas, al menos hasta hoy, para controlar de alguna manera con eficacia los aspectos dominantes de las franjas de poder globalizado. 
Como lo he insinuado y lo he dicho varias veces ya en este trabajo, solamente los estados de derecho altamente evolucionados, que se han aglutinado bajo la forma de comunidades políticas y económicas como es la Unión Europea, comienzan a tener a través de nuevas instituciones comunitarias algunos instrumentos de contralor a los efectos de las franjas de poder globalizado.

Es así que se evidencia en esas comunidades aglutinadas la aparición de fuerzas con asiento gubernamental y otras con respaldo en la propia sociedad tendiente al cuidado del medio ambiente ecológico. Así se va creando mentalidad colectiva que comienza a tener capacidad y eficacia para intentar controlar algunos de los efectos de las franjas de poder globalizado. Sobre todo ante episodios de destrucción ecológica conocidos e impactantes.

Las reacciones de los estados de derechos y las sociedades frente a las franjas de poder energético vinculado con el petróleo van encontrando algunas fuerzas que se le oponen con relativo éxito ante los desastres ecológicos que las manipulaciones del transporte petrolero producen en el planeta.

Es este un muy pequeño ejemplo de respuestas a una franja de poder globalizado tecnológico de enorme poderío.

También las estructuras político jurídicas aglutinadas bajo la forma de comunidades como la europea, desarrollan algunos aspectos sanitarios que tienen a enfrentar las consecuencias de franjas de poder globalizado, como es el supuesto de zonas vinculadas con el tráfico de productos de alta tecnología y peligrosidad, como lo son, por ejemplo, todo lo referido a la energía atómica y sus aplicaciones prácticas para generar energía. Lo mismo sucede con el destino de los residuos atómicos.

No son muchos más los ejemplos que pueden ofrecerse para dar respuesta a la pregunta de cómo es posible la gobernabilidad, el estado de derecho y la vigencia de los derechos humanos, en un mundo en que la globalización por franjas crece de manera impresionante en su desarrollo y en su aplicación efectiva.

No es posible pensar en utopías como el gran Immanuel Kant lo sugirió en sus últimos años en Königsberg su tierra natal y donde desarrolló toda su vida. Un gobierno universal como garantía de la paz perpetua, no sólo es un imposible, sino que además es un enorme riesgo. Porque no existe ninguna garantía que ese gobierno universal no 
esté inmune de caer en tiranías. Los gobiernos son siempre gobiernos de hombres. Sean de estados naciones o de imperios, son siempre gobiernos de hombres. Y como tales perfectamente corruptibles.

La historia lo enseña hasta el hartazgo que es muy difícil, para no decir casi un imposible, que los gobiernos de hombres estén a salvo de prostituirse. $\mathrm{El}$ único ejemplo que tenemos a la vista y en forma más o menos relativa es el de los Estados Unidos que en sus más de doscientos años con gobiernos de hombres fue y es en gran proporción gobierno de estado de derecho. También existen en ese gran país ejemplos durísimos que prueban lo que va expuesto. La guerra civil de 1861-1865 no es equiparable a una tiranía, pero sí fue la más sangrienta de la historia desde que hay historia. El equilibrio, las libertades y las garantías y los controles en los Estados Unidos funcionarán. De ello no hay duda. Pero tampoco hay duda que funcionarán de fronteras para adentro y para los propios. Porque si se mira lo acaecido en estos más de doscientos años de libertad y de democracias, admirables sin duda para los propios norteamericanos, no tanto para los otros, de fronteras para adentro cuando se observa el accionar de los gobiernos de USA de fronteras para afuera, se constatan horrorosas violaciones de derechos y garantías. México tiene algo para contar al respecto de este tema. Los países de Centroamérica también y muchos países del Asia lejana y cercana pueden continuar los relatos que preceden. Para hacer breve el tema, Estados Unidos es una democracia que respeta los derechos humanos aceptablemente para adentro, pero deja mucho que desear de fronteras para afuera.

Estos cursos de acción nada tienen de original. El imperio inglés fue igual, pero en verdad muchísimo peor que Estados Unidos en lo que se refiere a las actuaciones de fronteras para afuera- Con esos ejemplos a la vista, que desde cierto ángulo son valederos para el tema central en análisis, resulta que en su consecuencia la globalización por franjas no tiene hasta hoy la posibilidad de ser controlada en sus efectos sobre la gobernabilidad de los estados de derecho que esas franjas de globalización afecten. Sólo es factible pensar, como ya ha sido desarrollado, que es posible atemperar los efectos de las franjas de globalización cuando los estados de derecho están aglutinados política y económicamente como es el supuesto de la Comunidad Europea. Pero entiéndase bien estamos hablando de disminuir algunos efectos no de controlarlos. Porque controlarlos todavía ni siquiera la comunidad mencionada lo puede lograr. 
Reitero entonces que no existe la posibilidad de gobiernos mundiales posibles que puedan controlar las franjas de poder globalizado y las aglutinaciones regionales evidencian hasta hoy solamente capacidad de disminuir efectos.

Consecuentemente globalización y estado de derecho y vigencia de los derechos humanos y gobernabilidad liberada de los efectos de la globalización, son en nuestro tiempo todavía verdaderas asignaturas pendientes, si es que se pretende compatibilizar con signo positivo las intervinculaciones de aquella realidad que es la globalización con los intentos de libertad y garantía que son el estado de derecho y la vigencia de los derechos humanos.

No queda en nuestros días ningún otro refugio efectivo para posibilitar la subsistencia de los estados de derecho y de los derechos humanos frente a los efectos dominantes de la globalización por franjas, que la mostración impactante de la temática en desarrollo en sus reales dimensiones. Servirá para intentar que esa mostración evidencia los graves riesgos que se corren sobre todo en materia de gobernabilidad de las comunidades humanas condicionadas por la globalización. Entiendo que es la mejor metodología hoy realmente factible.

Nuevamente la vieja idea de la Enciclopedia que la liberación del hombre se logra por el camino de la educación es absolutamente aplicable.

Pero ello siempre y cuando se sepa diferenciar en toda su trascendencia e importancia los procesos de instrucción de los aspectos formativos de la educación.

Los riesgos enormes que traen las consecuencias de las tres grandes invasiones que el hombre ha producido en el siglo XX, y sobre todo en su segunda mitad, muestran que el más grande de los peligros del crecimiento de las ciencias puras, radica en la necesidad que la educación y en general el mundo de la cultura progrese y crezca para llegar de alguna suerte a equilibrar los enormes avances de las ciencias puras y de experiencia.

El hombre en estos últimos cuatro siglos y sobre todo en el que acaba, ha realizado enormes progresos en el ámbito de las ciencias puras y de las ciencias de experiencia.

En cambio en el mundo de las ciencias de cultura, lamentablemente el progreso habido es sideralmente minúsculo frente al de aquellas otras. 
La gran respuesta al tema de la gobernabilidad en un mundo globalizado en el que se pretenda la vigencia del estado de derecho y de los derechos humanos tiene a mis ojos como única respuesta la que va señalada. La imprescindible necesidad que crezca realmente el ámbito de la cultura humana en sus efectos individuales y colectivos.

Evidentemente es bastante deteriorante en sus posibilidades de eficacia inmediata la conclusión enunciada. Pues los progresos culturales y sobre todo sus efectos sobre la base de la educación requieren de enormes períodos de tiempo y están librados a los avatares que la historia muestra, en el sentido que la humanidad al tiempo que presencializa un progreso acumulativo en lo científico vinculado a las ciencias puras y a las de experiencia, exhibe una marcha a veces con retroceso en lo cultural. Y cuando lo cultural avanza, ese impacto lo hace a muy baja celeridad y con resultados bastante poco satisfactorios.

Globalización, estado de derecho y derechos humanos, quedan también como asignaturas pendientes para las generaciones futuras.

\section{Necesidad de no demonizar la globalización}

Entiendo que a más de todo lo expuesto y de las dificultades evidentes para compatibilizar globalización, estado de derecho y gobernabilidad, los graves inconvenientes individualizados no deben llevar a demonizar a la globalización.

Es muy trascendente visualizar la necesidad de comprender que la globalización en sí misma es sin duda un fenómeno que tiene mucha originalidad. $Y$ es el resultado inexorable de las tres invasiones que el hombre produjo en el siglo XX. A ellas responden los presupuestos tecnológicos aplicados que son resultado de las ciencias puras extraordinariamente desarrolladas en ocasión de esas tres invasiones. En definitiva hay que tener la capacidad de comprender en profundidad que la globalización es un momento en la evolución de los efectos de la inteligencia del hombre aplicada al conocimiento de la naturaleza y sus incidencias para con la convivencia.

Pero al mismo tiempo es menester comprender y comprobar teniendo a la historia como ámbito ineludible de conocimiento para el estudio de la temática de la globalización, que visualizada desde el 
ángulo de su importancia como impacto en la civilización y cultura del hombre, semeja algunos otros momentos históricos en los que también se vivieron etapas de desconcierto más o menos análogas a las que produce hoy la globalización.

No hay duda alguna que el hombre del siglo XIII sobre todo en la Europa occidental, cuando se enfrentó al uso de la pólvora en los campos de batalla y vio el proceso de deterioro acelerado de las estructuras bélicas de defensa de la sociedad de su época, tuvo la impresión profunda que su mundo tocaba su fin y se destruían los sistemas de lealtades de la sociedad feudal que integraba. La visión de las grandes construcciones de fortalezas y castillos que caían unas tras otras, a raíz de los efectos del uso de la pólvora en la guerra, destruían su mundo totalmente. Es cierto que cambió los sistemas bélicos. Es cierto que se modificó grandemente la sociedad. Es cierto que perdió valor la caballería y sobre todo la figura del líder individual. Pero también es cierto que muy prontamente la sociedad se auto transformó.

Absorbió el impacto que parecía en su primer momento poco comprensible y de consecuencias indeterminables en su trascendencia. Las formas sociales estamentarias, sin duda se alteraron. El feudalismo entró en decadencia. Se concentraron los centros de poder disminuyendo en número y aumentando en eficacia los que subsistieron. Los cambios fueron enormes y trascendentes. Fue uno de los orígenes del nacimiento de los estados naciones. Todo ello es cierto. La humanidad de la Europa de occidente mutó las formas de relaciones de poder. Pero el poder en sí mismo en su esencia continuó como tal, aunque con menos titulares decisorios y mayor intensidad de ejercicio de ese poder. También se aplicó el ámbito territorial del nuevo poder concentrado.

Cuando apareció la imprenta, la cultura de Occidente en el siglo $\mathrm{XV}$ recibió esa enorme novedad, casi sin apercibirse en sus primeros momentos. Pero cuando en menos de cincuenta años se produjo la gran expansión del nuevo sistema de transmitir conocimientos por escrito, sin duda el impacto fue enorme y sus consecuencias crecieron geométricamente en muy pocos años. La expansión creciente e ilimitada de la cultura escrita que significó la imprenta, fue uno de los vehículos más trascendentes que vitalizaron el proceso ideológico que se denominó Renacimiento y que se denominó Reforma.

Esos dos impactos en la cultura de occidente, más las consecuencias del descubrimiento y conquista de América produjeron a comien- 
zos del siglo XVI y todo a lo largo del mismo y hasta la paz de Westfalia de 1648, trajeron como consecuencia cambios esenciales en las relaciones de poder en la Europa de occidente y también en las formas de vida de las sociedades de aquellos tiempos.

No hay duda alguna de los tránsitos de dominación política, económica y social que los tres momentos históricos señalados produjeron en la cultura del hombre.

Es evidente que se alteró inclusive la impronta genético-cultural del hombre de occidente.

Pero un conjunto de elementos de respuesta como la contrarreforma, el barroco y la aceptación del pluralismo religioso, posibilitaron el nuevo mundo que aquellos grandes impactos habían dado origen.

No hay duda que la globalización semeja grandemente, no en sí misma, pero sí en sus epifenómenos, los ejemplos enunciados.

Y de la misma manera que aún cuando en los tiempos de cada uno de esos procesos no faltaron inteligencias que demonizaron esas enormes novedades, la realidad es que la continuidad y mutaciones de esas sociedades humanas, no sólo dejaron de lado esas valoraciones negativas, sino que señalaron, como se señala hoy en la historia del devenir del hombre, que esos momentos de los grandes impactos mentados integran necesariamente el proceso de la evolución y mutaciones ineludibles de la inteligencia humana y de la aplicación a la vida de esos procesos.

Lo mismo acaece y acaecerá con la globalización, la que necesariamente ha de modificar no solamente las estructuras de las relaciones de poder en lo político, en lo económico, en lo financiero y esencialmente en lo tecnológico, sino que además este momento de la llegada de la globalización por franjas será visualizado en el futuro, como nosotros lo hacemos, con relación a los momentos agonales de la historia del hombre que va recordados.

Por las razones expuestas entiendo entonces que es absolutamente improcedente demonizar la globalización. Semejante visión no solamente obnubila, sino que es notoriamente inútil, ineficaz y carece de destino. Tan inútil como fue en el pasado las demonizaciones de los grandes momentos de la historia del hombre que se han precisado como ejemplos valiosos.

Sin duda la historia del hombre, reconoce muchos otros supuestos que pueden ser agregados como analogías trascendentes para com- 
prender que la globalización es una realidad del tiempo histórico que en suerte nos toca vivir.

Como última reflexión deseo señalar que visto que como para «todo contemporáneo su contemporaneidad es confusa", somos muy malos testigos de la globalización en sí misma y sobre todo de sus efectos y de las mutaciones que se van produciendo.

Buenos Aires, 20 de noviembre de 2000 